\section{High Precision Carbon Dioxide and Oxygen Measurements Onboard of a Passenger Airplane}

Markus Leuenberger ${ }^{\star a}$, Luca Valentino ${ }^{a}$, Peter Nyfeler ${ }^{a}$, Hanspeter Moret ${ }^{\mathrm{a}}$, and the CARIBIC Team ${ }^{\mathrm{b}}$

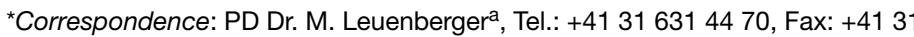
63187 42, E-Mail: leuenberger@climate.unibe.ch

aDivision of Climate and Environmental Physics, Physics Institute, University of Bern, Sidlerstrasse 5, CH-3012 Bern; b Max Planck Institute for Chemistry, Atmospheric Chemistry Division, Joh.-Joachim-Becher-Weg 27, D-55128 Mainz, Germany, Tel.: +496131305 0, Fax: +496131305 388

Keywords: Carbon cycle $\cdot$ Climate change $\cdot$ Fuel cell $\cdot$ Troposphere-stratosphere exchange

It is well known that emissions of fossil fuels lead to an enhancement of the Earth's greenhouse effect. Therefore, it is important to improve our knowledge about the carbon cycle, in particular the distribution of carbon dioxide in the atmosphere. Until recent years, mainly ground-based measurements were performed. Hence information about vertical distribution was lacking. In order to learn more about tropospheric $\mathrm{CO}_{2}$ at high altitudes, we took advantage of the logistics of the already running CARIBIC project (http://www.caribic-atmospheric.com). Oxygen concentration - an additional constraint for the carbon cycle - is linked to variations in $\mathrm{CO}_{2}$ due to photosynthesis/respiration processes as well as fossil fuel emissions. There are different principles for continuous oxygen determination, but most are vibration dependent and not suitable for moving platforms. We decided to use the fuel cell technology for our precise oxygen measurements and a conventional infrared absorption instrument for $\mathrm{CO}_{2}$.

The principle of the electro-chemical cell or fuel cell is based on the oxidation of a light acidic fluid within the cell producing a small electron current, which is transformed into a small voltage in the $\mathrm{mV}$ range over a resistance. The output of the fuel cell varies linearly with the oxygen content of the sample.

Annual changes in $\mathrm{CO}_{2}$ are in the order of 1-2 ppm, therefore variations in oxygen are of similar absolute magnitude. This corre-

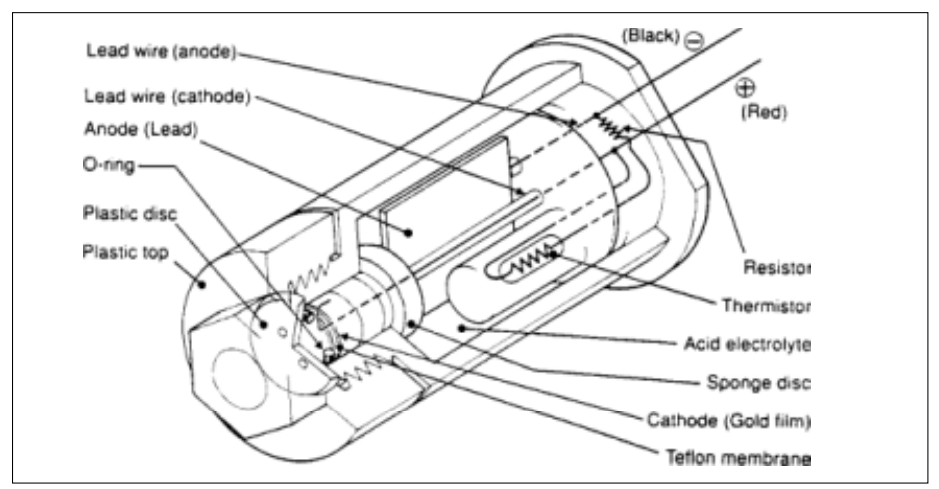

Design of the fuel cell for oxygen monitoring (Figaro, USA, Inc.) sponds to changes in the order of 0.0001 percent oxygen at a mean concentration of 20.95 percent. In order to achieve this precision temperature, pressure and gas flow have to be controlled to the highest level possible. The graph documents a comparison of two oxygen technologies, the fuel cell and the paramagnetic principle for a laboratory experiment. Despite an offset, which is calibration dependent, a good consistency was observed.

Our instrument is mounted on a cargo-container of a Lufthansa Airbus passenger airplane. Up to now about 60 flights have been performed. Results have shown that the precision for oxygen is not yet reached in comparison to $\mathrm{CO}_{2}$, mainly because of the high temperature sensitivity of the fuel cells. A long-term temperature stability of $0.01{ }^{\circ} \mathrm{C}$ is required.

\section{Reference}

Received: September 26, 2006

C.A.M. Brenninkmeijer, F. Slemr, C. Koeppel, D.S. Scharffe, M. Pupek, J. Lelieveld, P. Crutzen, A. Zahn, D. Sprung, H. Fischer, M. Hermann, M. Reichelt, J. Heintzenberg, H. Schlager, H. Ziereis, U. Schumann, B. Dix, U. Platt, R. Ebinghaus, B. Martinsson, P. Ciais, D. Filippi, M. Leuenberger, D. Oram, S. Penkett, P. van Velthoven, A. Waibel, Eos Trans. AGU 2005, 86(8), 77, 10.1029/2005EO080001.

\section{Acknowlegements:}

We would like to thank the financial support from the Gebert Ruf Stiftung.

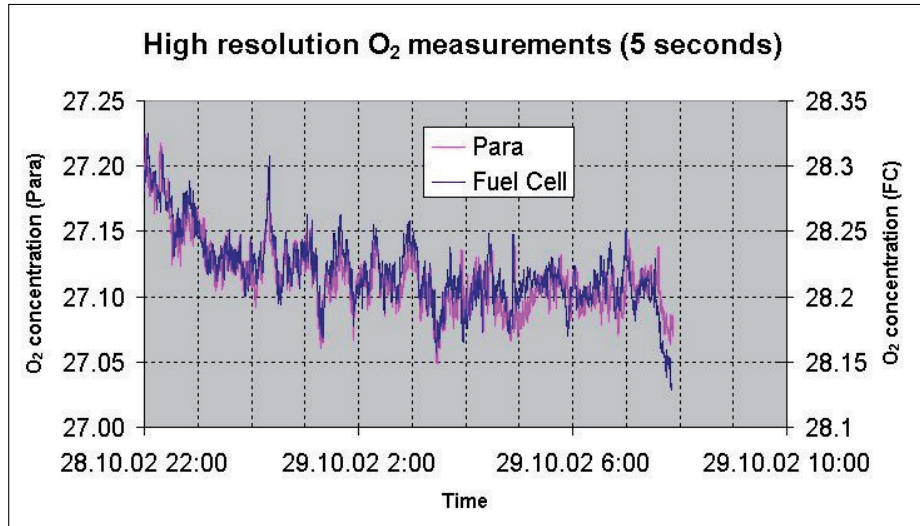

Comparison between the paramagnetic and fuel cell method

View of the fuel cell setup in an Airbus passenger airplane

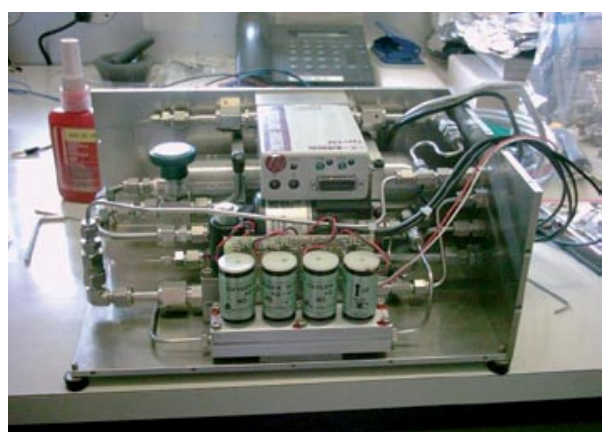

